\title{
The evolution and clinical importance of scar in hypertrophic cardiomyopathy - a 7 year CMR follow-up study
}

Giovanni Quarta ${ }^{1 *}$, Agata Grasso ${ }^{2}$, Ferdinando Pasquale ${ }^{1}$, Andrew S Flett ${ }^{1}$, Dan Sado ${ }^{1}$, Elena b ${ }^{3}$, Cono Ariti ${ }^{4}$, Sanjay K Prasad ${ }^{2}$, Perry M Elliott ${ }^{1}$, James C Moon ${ }^{1}$

From 2011 SCMR/Euro CMR Joint Scientific Sessions

Nice, France. 3-6 February 2011

\section{Introduction}

Fibrosis is a key histopathological component of hypertrophic cardiomyopathy (HCM). Fibrosis, detected by CMR late gadolinium enhancement (LGE) contributes to diastolic dysfunction, ischaemia, atrial fibrillation, progression to heart failure, sudden cardiac death and is associated with exercise intolerance.

\section{Purpose}

We sought to track long term changes in LGE by CMR in HCM and understand its clinical significance.

\section{Methods}

Sixty patients with HCM underwent CMR in 2001-2003. Twelve of these patients (age $42.0 \pm 18.7$ years) underwent two CMRs at least 6 years apart (mean $7.4 \pm 0.4$ years). Follow up was not completed in the other 48 due to: 6 deaths, 1 cardiac transplantation, 17 device implantations (ICD, PPM), 8 declined; 6 lost to follow up; 4 had a normal follow-up scan; 6 index CMR not available. Morphological parameters (maximal wall thickness, LV mass, EF, LV volumes, LA size, SAM, LVOT obstruction) were measured by two independent observers. The entire short-axis LGE stack of images were analyzed quantitatively with MRI-MASS (Medis, Leiden, The Netherlands, FWHM technique to calculate LGE\% total and per segment).

\section{Results}

Five patients (42\%) had no LGE at baseline and three of these had none at follow-up. In all other patients, LGE

${ }^{1}$ University College London Hospitals Trust, London, UK

Full list of author information is available at the end of the article either appeared de-novo (two) or increased during followup (mean difference $20 \pm 14 \%$, range 5-52\%). Baseline LGE correlated with adverse remodelling: decrease in maximal wall thickness (linear association, $\mathrm{p}=0.001$ ) and LV mass (linear association, $\mathrm{p}=0.05$ ); LV EF tended to decrease and

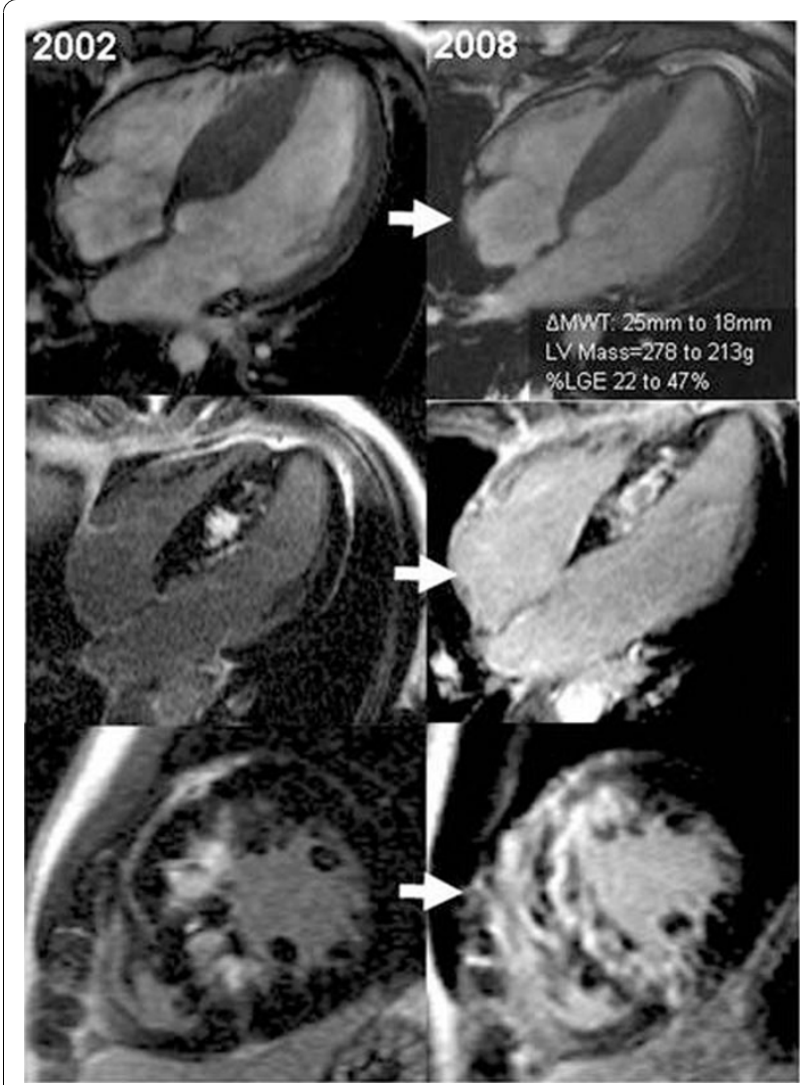

Figure 1 


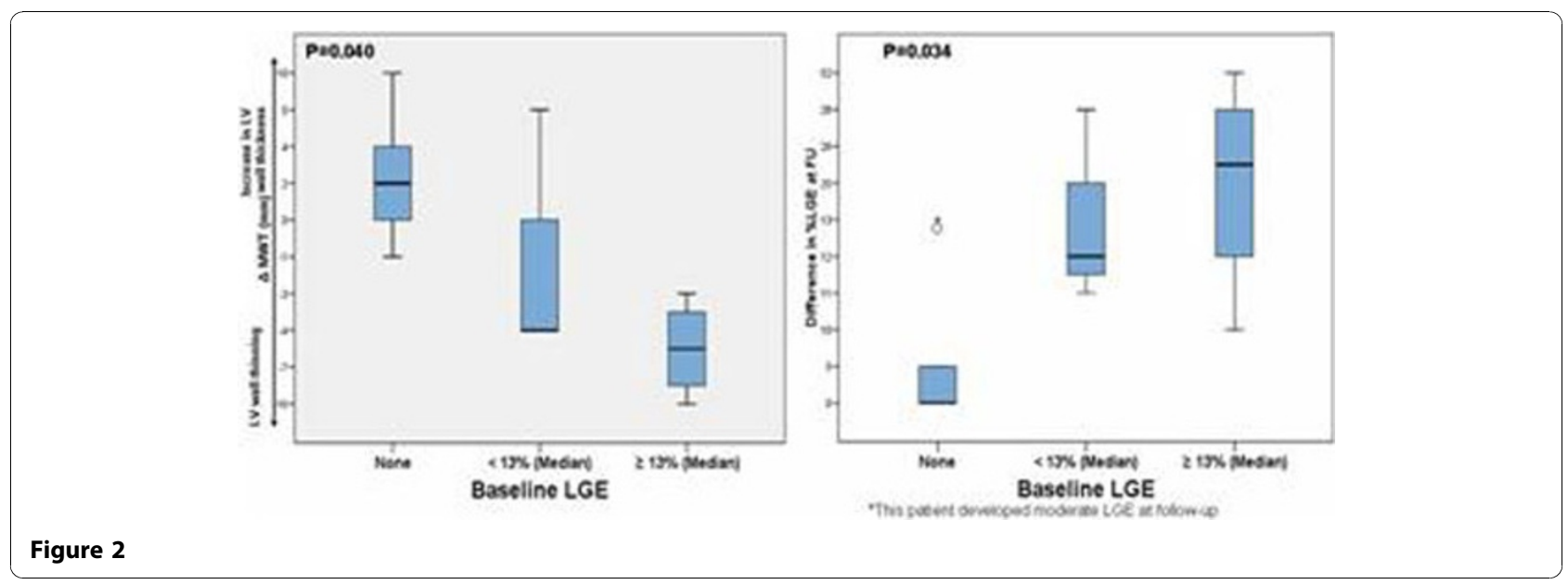

LVEDV tended to increase with increasing LGE at baseline, but did not reach statistical significance. The presence of LGE at baseline was strongly associated with worsening of LGE at follow up $\left(\mathrm{R}^{2}=0.64, \mathrm{p}=0.002\right)$. By segmental analysis, LGE increased on average by $13.8 \pm 22.5 \%$, $(\mathrm{p}<0.001)$. The amount of LGE in the segment at baseline and the total percent of LGE at baseline were strongly associated with the amount of LGE at follow up $\left(\mathrm{R}^{2}=0.54, \mathrm{p}<0.001\right)$. Segmental baseline \%LGE was strongly associated with the increase of LGE $(\mathrm{p}=0.016)$. Figures 1 and 2

\section{Conclusions}

Over 7 years, HCM LGE increases. Baseline LGE predicts adverse remodelling. LGE begets LGE - with baseline LGE predicting future increases in LGE.

\section{Author details}

${ }^{1}$ University College London Hospitals Trust, London, UK. ${ }^{2}$ Cardiovascular Magnetic Resonance, Royal Brompton and Harefield NHS Foundation Trust, London, UK. ${ }^{3}$ Azienda Ospedaliera "Spedali Civili", Brescia, Italy, ${ }^{4}$ London School of Hygiene and Tropical Medicine, London, UK. ${ }^{4}$ London School of Hygiene and Tropical Medicine, London, UK.

Published: 2 February 2011

Submit your next manuscript to BioMed Central and take full advantage of:

- Convenient online submission

- Thorough peer review

- No space constraints or color figure charges

- Immediate publication on acceptance

- Inclusion in PubMed, CAS, Scopus and Google Scholar

- Research which is freely available for redistribution 